\title{
Long-Term Impact Of On-Demand Professional Development On Student Performance: A Longitudinal Multi-State Study
}

Steven H. Shaha, Center For Policy \& Public Administration, USA

Kelly F. Glassett, University of Utah, USA

Heather Ellsworth, Brigham Young University, USA

\begin{abstract}
The long-term effects of Professional Development (PD) on educators' ability to affect student performance remain virtually unstudied. This quasi-experimental, longitudinal study compared student achievement scores from 25 states and 78 school districts over multiple years for schools whose teachers used an online, on-demand professional development offering. The objective was to evaluate to what degree student scores might improve, decline, or plateau with participation in professional development over multiple years. Results showed significant gains in student performance across the number of years of participation, with significant continuation in growth across years. Findings validate a significant predictive relationship between the number of years educators participated in PD and improvements quantified in student performance. Inferences of findings to other PD approaches or offerings, or other student or educator populations or settings are discussed.
\end{abstract}

Keywords: Professional Development; Multivariate Statistical Methods; On-Demand Professional Learning; Long-Term

\section{BACKGROUND \& REVIEW OF THE LITERATURE}

Professional development (PD) for teachers has long been a key and logically positioned undertaking for improving teacher satisfaction, as well as hope for improved classroom instruction and student achievement (Ball \& Cohen, 1999; Cohen \& Hill, 2000; Corcoran, Shields, \& Zucker, 1998; Darling-Hammond \& McLaughlin, 1995; Elmore, 1997; Little, 1993; National Commission on Teaching and America's Future, 1996; Wayne et al., 2008; Yoon et al., 2007). However, calls for high-quality PD remain persistent, yet there is a continued shortage of proven programs, including PD offerings that are data-verified or characterized as coherent, active learning, of sufficient duration, content knowledge-focused, or reflective of reform (Birman et al., 2007; Garet et al, 2001; Loucks-Horsley et al., 1998; Shaha \& Ellsworth, 2014; U.S. Department of Education, 2001).

The single greatest criticism of PD is the overwhelming prevalence of single-shot, one-day workshops that often make teacher professional development "intellectually superficial, disconnected from deep issues of curriculum and learning, fragmented, and noncumulative" (Ball \& Cohen, 1999, pp. 3-4). Many argue that coherent infrastructure for PD and its evaluation is either absent or too limited and thus PD represents a "patchwork of opportunities - formal and informal, mandatory and voluntary, serendipitous and planned" (Wilson \& Berne, 1999, p.174). Such a critique is untenable for long-term or broad and generalizable PD success.

There is an unfortunate and unjustifiable lack of scientifically-based research that demonstrates quantified PD-driven improvement in student achievement. Substantive information and rigorous data on how PD programs affect student achievement is an urgent need. Yet, data-proven research in PD efficacy remains rare, reflecting 
statistically rigorous studies demonstrating PD impact on teacher efficacy toward actual student achievement (Fishman et al, 2003; Loucks-Horsley et al., 2003; Shaha et al., 2004; Shaha \& Ellsworth, 2014; Wilson \& Berne, 1999). Due to the lack of research, PD purchases continue to rely heavily or exclusively on unsubstantiated marketing materials or testimonials.

Despite all observations regarding PD and criticisms, several recent studies have verified significant growth in student performance associated with teacher participation in PD, particularly in online, on-demand offerings (Avalos, 2011; Buczynski \& Hansen, 2010; Desimone et al., 2002; Ingvarson et al., 2005; Shaha et al., 2004; Shaha \& Ellsworth, 2013; Wasik \& Hindman, 2011). Further, results from a handful of specific studies establish that the degree of teacher engagement in PD significantly affects the amount of improvement experienced in student performance, contrasting active participation versus more passive engagement based principally on video participation alone (Desimone et al., 2002; Darling-Hammond, 2004; Garet et al., 2001; King, 2002; Santagata, 2009; Shaha \& Ellsworth, 2014).

Therefore, data-backed scientific research has begun but needs to grow. What our industry needs are rigorous, substantive studies that establish the credibility and impact of PD offerings and participation. Furthermore, such proof should mature beyond a single year of impact and verify that gains are held over time, or even improved longitudinally, with ongoing PD participation or improved use and implementation.

The purpose of this research was to measure whether continued participation in PD over multiple years would have long-term, continued benefits in student achievement or whether impacts would plateau over time or even diminish. The goal was to quantify whether student gains were significant and sustained over time with continued teacher PD participation.

\section{METHODS}

The study design reflected a quasi-experimental, longitudinal design (Cook \& Campbell, 1979). School participation was defined as use of a single commercially available online, on-demand PD product widely used in the United States (PD $360 \AA$, Common Core $360 \AA$, and/or Observation $360 \AA$ ). This enabled teachers to engage in a breadth of activities ranging from instructional videos on teaching techniques to higher levels of participation, such as professional learning communities and posting and downloading PD-related materials.

Student performance data were gathered from publically available web sources. To overcome variations in assessment instruments across states and districts, comparative performance was analyzed as changes in the percentage of students classified as either "advanced" or "proficient" regardless of the test (no within-state changes in testing were noted within the sample for the data). Districts in the study met minimal inclusion requirements of an average of 90 minutes of voluntary PD participation annually, and only districts with more than a single year of PD participation were included. Data were aggregated into two-year increments for analysis to maximize sample sizes for statistical comparisons. All comparisons contrasted net gain in student performance from baseline or the last year pre-implementation.

All analyses were conducted using SPSS version 17.0 or higher (PASW Statistics; SPSS, 2009, with SAS used for confirmatory purposes when results were close to $\mathrm{p}<0.05$ ). Minimum level of statistical significance was determined a priori at $\mathrm{p}<0.05$. To ensure conservative interpretations, the $n$ for each statistical test was held to the number of districts and not to schools, educators, or students.

\section{RESULTS \& FINDINGS}

Final data included 78 districts from 25 states. Longevity among districts included ranged from two to seven years. The demographic distribution of the sample by Urban and Title I schools is shown in Table 1. 
Table 1: Demographic Mix By Years Of PD Participation

\begin{tabular}{|c|c|c|c|c|c|}
\hline & \multirow[b]{2}{*}{$\mathbf{N}$} & \multicolumn{2}{|c|}{ Urban } & \multicolumn{2}{|c|}{ Title 1} \\
\hline & & Pct & p-Value & Pct & p-Value \\
\hline 2-3 years & 22 & $18.2 \%$ & \multirow{3}{*}{$0.0374-5>2-3,6-7$} & $61.0 \%$ & \\
\hline 4-5 years & 45 & $33.3 \%$ & & $72.0 \%$ & \\
\hline 6-7 years & 11 & $18.2 \%$ & & $84.0 \%$ & $0.038 \quad 6-7>2-3$ \\
\hline
\end{tabular}

The comparative net change in mean student performance versus baseline showed consistent and significant growth across longitudinal groupings for both reading and math (see Table 2 and Figure 1). For reading in schools that had participated for only two to three years, there was an increase of 5.58 percent of students proficient or advanced. For the group participating four to five years, the increase in performance was 7.34 $(\mathrm{p}<0.042)$, and for six to seven years, performance increased by 12.77 percentage points $(\mathrm{p}<0.037)$.

Table 2: Net Change In Student Performance By Years Of PD Participation

\begin{tabular}{lccc|cc}
\hline & \multicolumn{2}{c}{ Reading Performance } & \multicolumn{2}{c}{ Math Performance } \\
\hline & N & Net Mean Change & p-Value & Net Mean Change & p-Value \\
\hline $\mathbf{2 - 3}$ years & 22 & 5.58 & & 2.90 & $\mathrm{p}=0.031$ \\
4-5 years & 45 & 7.34 & $\mathrm{p}=0.042$ & 6.92 & $\mathrm{p}=0.009$ \\
6-7 years & 11 & 12.77 & $\mathrm{p}=0.037$ & 12.14 & \\
\hline
\end{tabular}

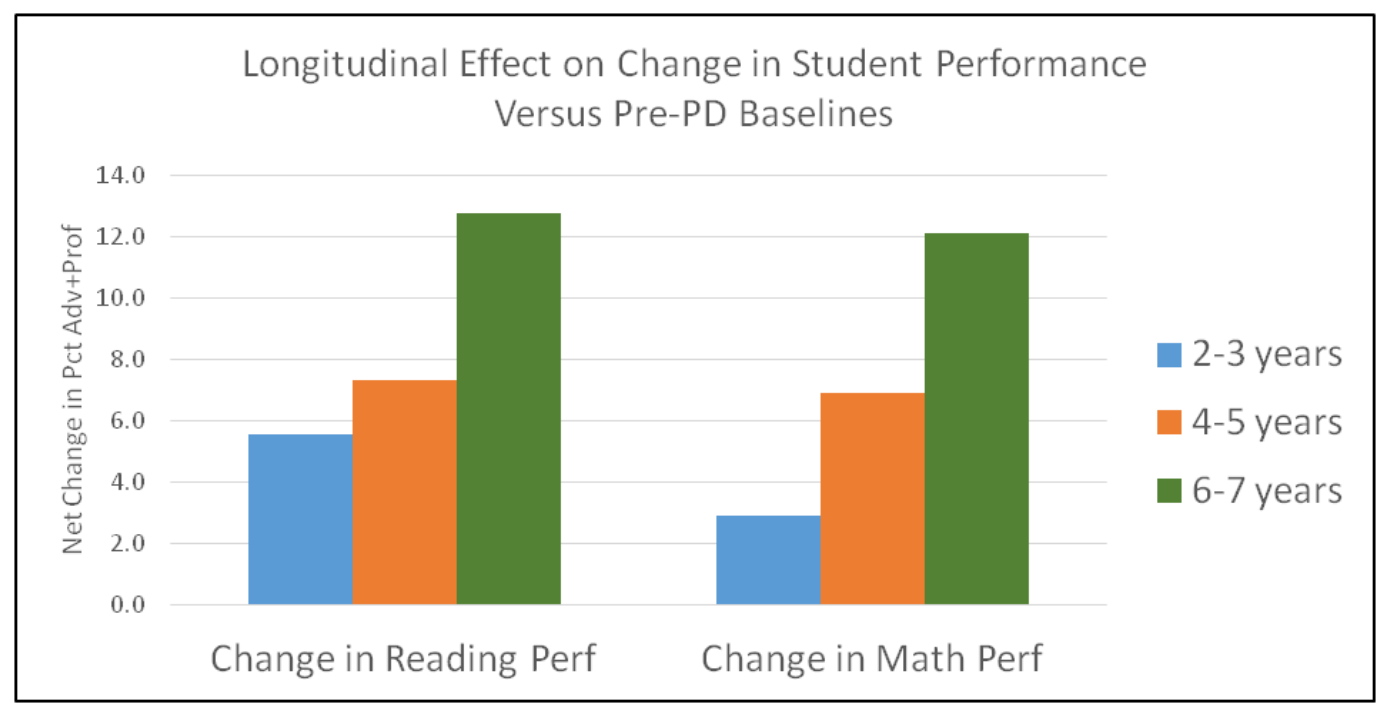

Figure 1: Net Change In Student Performance By Years Of PD Participation

For mathematics, the net mean change in student performance levels for schools that participated for two to three years was an increase of 2.90 in percent of students classified as proficient or advanced. For the group participating four to five years, the increase in performance was $6.92(\mathrm{p}<0.031)$, and for six to seven years, performance increased by 12.14 percentage points $(\mathrm{p}<0.009)$.

\section{CONCLUSIONS}

Districts in 25 states whose teachers actively participated in the online, on-demand PD offering experienced significant improvement in student achievement. Equally important, the longer the participation was maintained, the greater the growth that was experienced and sustained. Clearly, the data show that the longer teachers participated in the PD test, the greater the gains they experienced for their students. The degree of improvement leads to an interpretation that longer engagement is causal, rather than an alternative inference that continued improvement was causal to continued engagement.

Data from studies of PD consistently encourage that every educational institution spending on PD should ensure that such represents a genuine investment. Investments infer data wherein either the statistically proven 
successes of others or from within are incorporated into decision making to ensure data-driven assurances of promises beyond marketing tracts alone. In the absence of proof, money used represents only an expenditure or an outlay without substantive evidence of impact. The measure of impact cannot be based upon the happiness levels of participating teachers alone, as might be the case for in-person PD seminars or workshops. Rather, the measure of success should include or be expressed in impact upon students for better meeting the goals toward which teachers and schools are aimed. Spending on unmeasured PD remains a risk-PD is NOT an investment until it is evaluated and quantified and proven to impact teacher and school efficacy.

Whether these results are exclusive to this specific PD offering remains an open question. The answer will remain unknown until similar rigorous, statistically-backed studies are executed for other PD offerings and implementations. For now, this remains the only multi-state study in existence according to an exhaustive review of the literature, providing a basis in methodology and findings upon which comparative studies should be executed.

In conclusion, the efficacy and impact of teachers participating in PD can be, and should be, shown in readily interpretable statistical results. Educators continuously seek greater impact on students and PD can now be touted as an affirmative action in that crucial direction. Additionally, it is comforting that the lower-cost, more readily accessible capabilities of high engagement use of an online, on-demand PD offering has near-term and lasting impacts on the students relying on teachers.

\section{AUTHOR INFORMATION}

Professor Steven Shaha has done 100+ program evaluations for 35+ years on four continents - America, Asia, Australia and Europe. His work includes public, private, for-profit and not-for-profit sectors in various industries. Steve holds two masters degrees and doctorates in Research Methods \& Applied Statistics (PhD) and in Business Administration (DBA). He has presented 200+ conference papers, has 100+ peer-reviewed publications, and two books. He is a full professor and has taught at 18 universities, e.g., Harvard, Cambridge (UK), Princeton, Columbia, Cornell, UCLA, and Zayed University (UAE). He has helped non-educational organizations, including, e.g., Disney, Ritz-Carlton, RAND, Time-Warner, Intel, and IBM.

Email: Steve.shaha@allscripts.com

Dr. Kelly Glassett currently serves as the content specialist for School Improvement. Prior to his current position, he was an Associate Professor and Director of Teacher Education at SIUC. The focus of his scholarship and research activity has been directed toward teacher preparation, literacy and learning in $21^{\text {st }}$ century classrooms, and technology integration in educational environments. He has worked as a classroom teacher in K-12 settings for over fifteen years and taught at the collegiate level for over eight years. He has authored or coauthored over 35 peer reviewed articles and over 70 conference presentations on his research.

Email: Kelly.glassett@schoolimprovement.com

Heather Ellsworth recently graduated from Brigham Young University in Statistics. She has assisted Steven Shaha for the last year and a half in various research roles. Within that time, she participated in two peer reviews and one presentation.

Email: Ellsworth.heather@gmail.com

\section{REFERENCES}

1. Avalos, B. (2011). Teacher professional development in teaching and teacher education over ten years. Teaching and Teacher Education, 27(1), 10-20. doi:10.1016/j.tate.2010.08.007.

2. Ball, D. L., \& Cohe

3. n, D. K. (1999). Developing practices, developing practitioners: Toward a practice-based theory of professional development. In G. Sykes \& L. Darling-Hammonds (Eds.), Teaching as the learning profession: Handbook of policy and practice (pp. 30-32). San Francisco, CA: Jossey-Bass.

4. Birman, B., LeFloch, K. C., Klekotka, A., Ludwig, M., Taylor, J., Walters, K., Wayne, A., \& Yoon, K. S. (2007). State and local implementation of the No Child Left Behind Act, volume II-Teacher quality under NCLB: Interim report. Washington, D.C.: U.S. Department of Education, Office of Planning, Evaluation 
and Policy Development, Policy and Program Studies Service.

5. Buczynski, S., \& Hansen, C. B. (2010). Impact of professional development on teacher practice:

Uncovering connections. Teaching and Teacher Education, 26(3), 599-607. doi:10.1016/j.tate.2009.09.006.

6. Cohen, D. K., \& Hill, H. C. (2000). Instructional policy and classroom performance: The mathematics reform in California. Teachers College Record, 102(2), 294-343.

7. Cook, T. D., \& Campbell, D. T. (1979). Quasi-Experimentation: Design \& Analysis Issues for Field Settings. Houghton Mifflin Company: Boston.

8. Corcoran, T. B., Shields, P. M., \& Zucker, A. A. (1998). The SSIs and professional development for teachers. Menlo Park, CA: SRI International.

9. Darling-Hammond, L. (2004). Standards, accountability, and school reform. Teachers College Record, 106(6), 1047-1085.

10. Darling-Hammond, L., \& McLaughlin, M. W. (1995). Policies that support professional development in an era of reform. Phi Delta Kappan, 76(8), 597-604.

11. Desimone, L. M., Porter, A. C., Garet, M. S., Yoon, K. S., \& Birman, B. F. (2002). Effects of professional development on teacher's instruction: Results from a three-year longitudinal study. Educational Evaluation and Policy Analysis, 24(2), 81-112.

12. Elmore, R. F. (1997). Investing in teacher learning: Staff development and instructional improvement in Community School District \#2, New York City. New York, NY: National Commission on Teaching \& America's Future.

13. Fishman, B. J., Marx, R. W., Best, S., \& Revital, T. T. (2003). Linking teacher and student learning to improve profressional development in systematic reform. Teaching and Teacher Education, 19(6), 643658.

14. Garet, M. S., Porter, A. C., Desimone, L., Birman, B. F., \& Yoon, K. S. (2001). What makes professional development effective? Results from a national sample of teachers. American Educational Research Journal, 38(4), 915.

15. Ingvarson, L., Meiers, M., \& Beavis, A. (2005). "Factors Affection the Impact of Professional Development Programs on Teachers' Knowledge, Practice, Student Outcomes \& Efficacy" Australian Council for Educational Research. 13(10), January 2005.

16. King, K. P. (2002). Identifying success in online teacher education and professional development. The Internet and Higher Education, 5(3), 231-246. doi:10.1016/S1096-7516(02)00104-5.

17. Little, J. W. (1993). Teachers' professional development in a climate of educational reform. Educational Evaluation \& Policy Analysis, 15(2), 129-151.

18. Loucks-Horsley, S., Hewson, P. W., Love, N., \& Stiles, K. E. (1998). Designing professional development for teachers of science and mathematics. Thousand Oaks, CA: Corwin Press.

19. Loucks-Horsley, S., Love, N. S., Stiles, K. E., Mundry, S., \& Hewson, P. W. (2003). Designing professional development for teachers of science and mathematics. Thousand Oaks, California: Corwin.

20. National Commission on Teaching and America's Future. (1996). What matters most: Teaching for America's future. New York, NY: Author.

21. Santagata, R. (2009). Designing video-based professional development for mathematics teachers in lowperforming schools. Journal of Teacher Education, 60(1), 38-51.

22. Shaha S. H., \& Ellsworth, H. (2013). Multi-State, Quasi-experimental Study of the Impact of On-demand Professional Development on Students Performance. International Journal of Evaluation and Research in Education (IJERE). Vol.2, No. 4.

23. Shaha, S. H., \& Ellsworth, H. (2014). Predictors of Success for Professional Development: Linking Student Achievement to School and Educator Successes through On-Demand, Online Professional Learning. Journal of Instructional Psychology. Vol.40, No. 1.

24. Shaha, S. H., Lewis, V. K., O'Donnell, T. J., \& Brown, D. H. (2004). Evaluating professional development: An approach in verifying program impact on teachers and students. Journal of Research in Professional Learning, $1(1), 1$.

25. U.S. Department of Education. (2001). Teacher preparation and professional development: 2000. National Center for Education Statistics Report, No. 2001-088. Washington, DC: Author.

26. Wasik, B. A., \& Hindman, A. H. (2011). Improving Vocabulary and Pre-Literacy Skills of at-Risk Preschoolers through Teacher Professional Development. Journal of Educational Psychology 103(2), 45569. 
27. Wayne, A. J., Yoon, K. S., Zhu, P., Cronen, S., \& Garet, M. S. (2008). Experimenting with teacher professional development: Motives and methods.Educational researcher, 37(8), 469-479.

28. Wilson, S. M., \& Berne, J. (1999). Teacher learning and the acquisition of professional knowledge: An examination of research on contemporary professional development. Review of Research in Education, 24, 173-209.

29. Yoon, K. S., Duncan, T., Lee, S. W. Y., Scarloss, B., \& Shapley, K. L. (2007). Reviewing the Evidence on How Teacher Professional Development Affects Student Achievement. Issues \& Answers. REL 2007-No. 033. Regional Educational Laboratory Southwest (NJ1). 